\title{
Physical practice is associated with less functional disability in medical students with migraine
}

\author{
Renan B. Domingues ${ }^{1,2}$, Antônio Lúcio Teixeira ${ }^{2,3}$, Simone A. Domingues ${ }^{1}$
}

\begin{abstract}
The aim of this study was to investigate possible association between migraine and physical practice among 480 medical students who were submitted to a questionnaire about headaches and physical practices. Migraine diagnosis was assessed by ID-Migraine and functional disability was evaluated with MIDAS. The type (aerobic or strength training), the weekly frequency and the intensity of physical practice and body mass index (BMI) were assessed. There was a reduction in functional disability of migraine in students reporting physical practice (no physical practice - MIDAS $=8.81 \pm 1.40$, physical practice MIDAS=15.49 $\pm 1.78 ; P=0.03$ ). Frequency, intensity, and type of physical practices were not associated with functional impact of migraine. BMI did not correlate with migraine impact (normal weight - MIDAS=12.34 \pm 1.33 , overweight or obese - MIDAS=17.45 $\pm 3.86 ; P=0.33$ ). These results were confirmed by multivariate analysis. Our data suggest that physical practice is inversely related with functional disability of migraine in university students regardless of BMI.
\end{abstract}

Key words: aerobic physical practices, migraine, strength training, university students.

\section{A prática de exercícios físicos está associada a menor comprometimento funcional da migrânea entre estudantes de medicina}

\section{RESUMO}

O objetivo deste estudo foi avaliar a possível associação entre migrânea e a prática de exercícios físicos em uma população de 480 estudantes de medicina. $O$ rastreio de migrânea foi realizado com o inventário ID-migrânea e o comprometimento funcional da migrânea foi estimado com o inventário MIDAS. O tipo (aeróbica ou musculação), frequência e intensidade da atividade física e o índice de massa corpórea (IMC) foram determinados. Houve menor comprometimento funcional da migrânea nos estudantes que referiram praticar exercícios (não praticantes de exercícios - MIDAS $=8,81 \pm 1,40$,

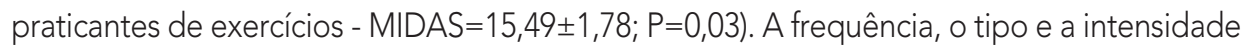
dos exercícios não se correlacionaram com o grau de comprometimento funcional da migrânea. Não houve associação entre o IMC e a severidade da migrânea (peso normal - MIDAS=12,34 $\pm 1,33$; sobrepeso ou obesidade - MIDAS=17,45 $\pm 3,86 ; P=0,33)$. Estes resultados foram confirmados por análise multivariada. Portanto, os dados sugerem uma relação inversa entre prática de exercícios físicos e grau de comprometimento funcional da migrânea em estudantes universitários, independentemente do IMC.

Palavras-chave: exercícios aeróbicos, migrânea, musculação, estudantes.

\section{Correspondence}

Renan Barros Domingues

Rua Prof. Almeida Cousin 125/1310

29055-565 Vitória ES - Brasil

E-mail:contato@renandomingues.med.br

Received 4 March 2010

Received in final form 21 July 2010

Accepted 29 July 2010
Migraine is a common and disabling primary headache disorder ${ }^{1-3}$. It has been suggested that physical practice benefits patients with migraine ${ }^{4-7}$. According to some authors, this benefit would be related with the increased production of beta endorphins and changes in the levels of nitric oxide during physical practice ${ }^{8,9}$. How- 
ever, most of the studies in this field were not controlled for the type, the frequency, or the intensity of the physical practices or were carried out with a small number of subjects ${ }^{10}$. Conversely, physical practice has been recognized as potential trigger of migraine attacks ${ }^{11-14}$. Therefore, there are no definitive conclusions about the actual effect of physical practice on the severity of migraine.

Migraine individuals with obesity or overweight have increased risk of greater frequency of migraine attacks ${ }^{15}$. Weight management has been suggested to be part of migraine treatment and aerobic physical practices are one of the main strategies for weight loss and weight control ${ }^{16,17}$. However, it is unknown whether reducing weight with physical practice can really improve migraine. Also, migraine has been recognized as a risk factor for cardiovascular disorders such as coronary heart disease and stroke $\mathrm{e}^{18}$ but it has not been established yet how physical practices affect the cardiovascular risk in subjects of migraine.

The objective of this study was to investigate the association of physical practice and weight on the functional disability of migraine among medical students.

\section{METHOD}

This is a cross sectional, community-based study. All medical students from the first to the fourth year of the Escola Superior de Ciências da Santa Casa de Vitória (EMESCAM), Vitória, Brazil received a questionnaire about headache and physical practice. The questionnaire was distributed to 480 students. The questionnaires were fulfilled by the students and they were asked to return the questionnaire to the principal investigator. Age, gender, and ethnicity were asked.

The students were asked about their physical practice in the last three months. Physical practices were classified as aerobic (including running, cycling, or swimming) or strength training. Weekly frequency of physical practice was recorded. Based on previously established physical practice protocols the frequency of exercising per week was divided in two groups: [1] less than three times a week, and [2] three or more times a week ${ }^{17}$. The intensity of the physical practice was classified according to the Borg 0-10 Ratio Scale of perceived exertion ${ }^{19}$. According to the perception of the intensity of exercising, the subjects were divided into two groups: 1 ) very light to somewhat hard, and 2) hard to exhaustive physical practices.

The Portuguese version of ID-migraine was used to screen for migraine diagnosis ${ }^{20}$. Those who gave positive responses to two or more of the three questions were considered to have migraine. The data of those considered to have migraine were compared with the data of those who reported no headache. The impact of migraine was assessed with migraine disability assessment (MIDAS) inventory ${ }^{21,22}$.
The body mass index (BMI) was calculated. The students with $\mathrm{BMI}<18.5$ were classified as underweight, 18.5 to 24.5 were classified as normal weight, 25 to 29.9 were classified as overweight, and 30 or greater were classified as obese $\mathrm{e}^{23}$. The students were divided in two categories according to the BMI: [1] underweight and normal weight, and [2] overweight and obese. The prevalence and impact of migraine in these categories were compared.

The Mann-Whitney U-test was used for the comparison of median MIDAS between the different groups according to the frequency and intensity of the practice of physical practices. The Chi-square test was used to compare the migraine prevalence in the different groups of students according to physical practices. The correlation between BMI and MIDAS was evaluated with Spearman test. An ordinal logistic regression was performed with the MIDAS as the dependent variable and gender, physical activity and BMI as covariates. All the calculations were performed using GraphPad Prism version 4.00 for Windows software (GraphPad Software Inc., San Diego, CA, USA). The level of significance was set at $\mathrm{p}<0.05$.

This study received full approval by the Ethics Committee on Research of the Escola Superior de Ciências da Santa Casa de Vitória (EMESCAM), Vitória, Brazil and informed consent was obtained from each participant.

\section{RESULTS}

Three hundred ninety nine students (83.1\%) completed the evaluation. Two hundred twenty eight $(57.1 \%)$ of them were women. Most of the students declared to be white (71.5\%), 24.9\% declared to be brown, and 3.6\% declared to be black. The mean \pm SD age of the students was $20.7 \pm 2.3$ years. One hundred fifty one students $(37.8 \%)$ reported regular physical practice. Physical practices types were: aerobic-114 students, strength training-105 students, both- 68 students. Forty two of the students (27.8\%) reported exercising less than three times a week and $109(72.2 \%)$ reported exercising three or more times a week. Fifty seven of these students (37.7\%) reported very light to somewhat hard physical practice, and 94 (62.2\%) reported hard to exhaustive physical practice. Most of the students (85.9\%) reported to have headache. One hundred thirty two (33\%) were classified as having migraine. The prevalence of migraine in the group of students practicing physical practice was not different of the group not exercising $(\mathrm{P}=0.4)$. The prevalence of migraine was not significantly different in the student groups according to the type of physical practice $(\mathrm{P}=0.8)$, frequency of physical practice $(\mathrm{P}=0.85)$, and intensity of physical practice $(\mathrm{P}=0.54)$. The only significant difference between the students with and without migraine was the proportion of women that was significantly higher among the students with migraine. The demographic and physical practice 
Table 1. Demographic and physical practice data of students with migraine and students without headache history.

\begin{tabular}{|c|c|c|c|}
\hline Students & Migraine $(\mathrm{N}=132)$ & Without headache $(\mathrm{N}=56)$ & $P$ value \\
\hline Age (mean $\pm S D$, min-max) & $21 \pm 0.2(17-30)$ & $20.8 \pm 0.3(17-29)$ & 0.45 \\
\hline \multicolumn{4}{|l|}{ Gender (\%) } \\
\hline Male & 17.5 & 14.4 & \\
\hline Female & 52.6 & 15.5 & 0.002 \\
\hline \multicolumn{4}{|l|}{ Ethnicity (\%) } \\
\hline White & 52.6 & 20.2 & \\
\hline Brown & 14.9 & 8 & \\
\hline Black & 2.7 & 1.6 & 0.60 \\
\hline \multicolumn{4}{|l|}{ Physical practice (\%) } \\
\hline Yes & 25.5 & 12.8 & \\
\hline No & 44.7 & 17 & 0.40 \\
\hline \multicolumn{4}{|l|}{ Type of physical practice (\%) } \\
\hline Aerobic & 21.9 & 11 & \\
\hline Strength training & 14.1 & 11 & \\
\hline Both & 26.5 & 15.5 & 0.8 \\
\hline \multicolumn{4}{|l|}{ Frequency(\%) } \\
\hline Less than 3 times a week & 20.8 & 11.1 & \\
\hline 3 or more times a week & 45.8 & 22.3 & 0.85 \\
\hline \multicolumn{4}{|l|}{ Physical practice (\%) } \\
\hline Very light to somewhat hard & 28.8 & 13.7 & \\
\hline Hard to exhaustive & 34.8 & 22.7 & 0.54 \\
\hline
\end{tabular}

SD: standard deviatation.

status differences between students with migraine and students reporting no headache are shown in Table 1.

Students with migraine who presented regular physical practice had a significantly lower disability as assessed by MIDAS than those who did not practice physical activities $(\mathrm{P}=0.03)$. The functional disability of migraine was also higher among women $(\mathrm{P}=0.03)$. The proportion of male students with migraine with or without physical activity (36.4 and 63.6, respectively) and the proportion of female students with migraine practicing and not practicing exercises (32.6 and 67.4, respectively) were not significantly different $(\mathrm{P}=0.7)$.

The impact of migraine was not significantly different among those reporting aerobic physical practice or strength training $(\mathrm{P}=0.54)$. There was no significant difference in the migraine functional disability of students reporting physical practice three or more times a week and those reporting physical practice less than three times a week $(\mathrm{P}=0.14)$. The impact of migraine was not significantly different among the students reporting very light to somewhat hard physical practice than those reporting hard to exhaustive physical practice $(\mathrm{P}=0.96)$. The functional disability of students reporting and not reporting physical practice is shown in Table 2.
Seventeen students (4.3\%) were classified as underweight, 301 (75.4\%) were classified as normal weight, 75 (18.8\%) as overweight, and $6(1,5 \%)$ as obese. The prevalence of migraine was not significantly different between those classified as underweight and normal weight than among those classified as overweight and obese $(\mathrm{P}=0.5)$. The impact of migraine among the students classified as underweight or normal weight was not significantly different that among those classified as overweight or obese $(\mathrm{P}=0.34)$. The functional impact of migraine among overweight and obese was not significantly different of the functional impact of migraine among under or normal weight students $(\mathrm{P}=0.33)$ (Table 2). Furthermore there was no correlation between BMI and MIDAS ( $\mathrm{P}=0.38)$. A multivariate analysis confirmed these results showing that gender and physical activity influence the severity of migraine, as assessed by MIDAS, but not the weight status (Table 3).

\section{DISCUSSION}

We have found a lower migraine functional disability among medical students reporting regular physical practice. We also have found that female students had higher migraine functional disability. These two variables 
Table 2. Functional disability of migraine, as assessed by the MIDAS, according to the physical practice status and body mass index.

\begin{tabular}{|c|c|c|}
\hline Students with migraine & $\begin{array}{c}\text { MIDAS } \\
(\text { mean } \pm S D)\end{array}$ & $P$ \\
\hline \multicolumn{3}{|l|}{ Gender } \\
\hline Male $(n=33)$ & $8.8 \pm 1.7$ & \\
\hline Female $(n=99)$ & $14.9 \pm 1.6$ & 0.03 \\
\hline \multicolumn{3}{|l|}{ Physical practice } \\
\hline Yes $(n=48)$ & $8.81 \pm 1.40$ & \\
\hline No $(n=84)$ & $15.49 \pm 1.78$ & 0.03 \\
\hline \multicolumn{3}{|l|}{ Physical practice } \\
\hline Aerobic $(n=17)$ & $6.8 \pm 1.6$ & \\
\hline Strength training $(n=12)$ & $13.6 \pm 3.9$ & \\
\hline Both $(n=19)$ & $8.2 \pm 2.4$ & 0.54 \\
\hline \multicolumn{3}{|l|}{ Physical practice } \\
\hline Less than 3 times a week $(n=15)$ & $14.33 \pm 1.58$ & \\
\hline 3 or more times a week $(n=33)$ & $9.86 \pm 1.91$ & 0.14 \\
\hline \multicolumn{3}{|l|}{ Physical practice } \\
\hline Very light to somewhat hard $(n=22)$ & $9.85 \pm 2.50$ & \\
\hline Hard to exhaustive $(n=26)$ & $8.00 \pm 1.45$ & 0.96 \\
\hline \multicolumn{3}{|l|}{ BMI } \\
\hline Underweight and normal $(n=109)$ & $12.34 \pm 1.33$ & \\
\hline Overweight and obese $(n=23)$ & $17.45 \pm 3.86$ & 0.33 \\
\hline
\end{tabular}

SD: standard deviatation; BMI: body mass index.

were independently associated with higher MIDAS scores since the proportion of male and female migraneurs practicing and not practicing exercises were not statistically significant. There were not significant differences when analyzed separately type of physical practice and intensity of physical practice. The students reporting physical practice 3 times or more a week had a lower functional disability of migraine but this difference was not significant. In a representative sample of the Brazilian population, Queiroz et al. found that people reporting physical practice 3 or more times a week had a lower prevalence of chronic daily headache with migranous features ${ }^{24}$, however, these authors did not assess functional disability. The present study shows an inverse association between the migraine functional disability and the regular practice of physical practice.

It has been shown that overweight and obese migraneurs have an increased risk of having more frequent migraine attacks and chronic migraine ${ }^{15}$. If obesity is an exacerbating factor for migraine and if the practice of physical practices reduces the risk of obesity ${ }^{16}$ it could be argued that physical practice reduces the impact of migraine by reducing weight. In our study the overweight and obese students had a higher functional disability related to migraine, however, this difference was not statistically significant. Therefore, the present study does not support the hypothesis that physical practice benefits migraneurs by reducing weight and suggests that physical practice may have an independent role in the improvement of migraine.

Our study has some clear limitations. The ID-migraine is a screening tool. Although it has been validated in Portuguese language it has not the same accuracy than a clinical evaluation by a headache expert using the International Headache Criteria ${ }^{25}$. The evaluation of the practice of physical practices was based on retrospective information and not on a validated tool. The Borg 0-10 Ratio Scale of perceived exertion is a subjective assessment tool and does not measure physiologic variables during the physical practice, such as heart rate and blood pressure. This study was conducted in a specific community so that the present data can not be generalized. Also, this type of study does not allow the definition of a precise causal relationship. Therefore it remains to be established if the regular practice of physical activity has a beneficial impact on migraine or if more severe migraine picture reduces physical activity due to exercise-induced pain. In either case this relationship is relevant. If physical practice improves migraine it should be recommended to migraneurs. If migraine reduces physical practice it may explain, at least in part, why migraine is a risk factor for cardiovascular disorders such as coronary disease and stroke ${ }^{18}$. It has been established that physical activity under medical supervision and follow-up reduces the risk of such diseases ${ }^{26}$. However, there are not prospec-

Table 3. Ordinal regression analysis of the variables related to the severity of migraine, as assessed by the migraine disability assessment.

\begin{tabular}{lccc}
\hline & p value & Odds ratio & 95\% Confidence interval \\
\hline Gender & 0.005 & 2.98 & $1.39-6.38$ \\
Physical activity & 0.024 & 2.27 & $1.12-4.63$ \\
Underweight & 0.534 & 0.41 & $0.02-6.92$ \\
Normal weight & 0.395 & 2.62 & $0.28-24.24$ \\
Overweight & 0.132 & 6.19 & $0.58-66.49$ \\
\hline
\end{tabular}


tive studies evaluating the role of physical activity in the relationship between migraine and cardiovascular disorders. Only prospective and controlled studies evaluating the impact of regular physical practice on migraine severity can firmly establish the direction of the association.

In conclusion, when analyzing the influence of gender, physical practice, frequency, type, intensity of physical practice, and weight on the functional impact of migraine among medical students we have found that only gender and physical practice were independently related with greater disability. Considering this and all the very well known benefits of physical practice the present study suggests that migraneurs should be encouraged to practice physical exercises.

\section{REFERENCES}

1. Lipton RB, Stewart WF, Diamond S, Diamond SL, Reed W. Prevalence and burden o migraine in the United States: data from the American Migraine Study II. Headache 2001;41:646-657.

2. Queiroz LP, Peres MF, Piovesan EJ, et al. A nationwide population-based study of migraine in Brazil. Cephalalgia 2009;9:642-649.

3. Domingues RB, Cezar PB, Schmidt Filho et al. Prevalence and impact of headache and migraine among Brazilian Tupiniquim natives. Arq Neuropsiquiatr 2009;67:413-415.

4. Van-Gijin J. Relief of common migraine by physical practice. J Neurol Neurosurg Psychiatry 1987;50:1700-1701.

5. Kumar KK. Physical practice for prophylaxis of migraine. Headache 1988; 28:228.

6. Dittrich SM, Günther V, Franz G, Burtscher M, Holzner B, Kopp M. Aerobic physical practice with relaxation: influence on pain and psychological well-being in female migraine patients. Clin J Sport Med 2008:18:363-365.

7. Varkey E, Hagen K, Zwart J-A, Linde M. Physical activity and headache: results from the Nord-Trøndelag Health Study (HUNT). Cephalalgia 2008;28: 1292-1297.

8. Koseoglu E, Akboyraz A, Soyuer A, Ersoy AO. Aerobic physical practice and plasma beta endorphin levels in patients with migrainous headache without aura. Cephalalgia 2003;23:972-976.

9. Narin SO, Pinar L, Erbas D, Ozturk V, Idiman F. The effects of physical prac- tice and physical practice-related changes in blood nitric oxide level on migraine headache. Clin Rehabil 2003;17:624-630.

10. Busch V, Gaul C. Physical practice in migraine therapy: is there any evidence for efficacy? A critical review. Headache 2008;48:890-899.

11. Indo T, Takahashi A. Swimmer's migraine. Headache 1990;30:485-487.

12. Fukui PT, Gonçalves TR, Strabelli CG, et al. Trigger factors in migraine patients. Arq Neuropsiquiatr 2008;66:494-499.

13. Thompson JK. Physical practice-induced migraine prodrome symptoms. Headache 1987;27:250-251.

14. Nadelson C. Sports and physical practice-induced migraines. Curr Sports Med Rep 2006;5:29-33.

15. Bigal ME, Lipton RB. Obesity and chronic daily headache. Curr Pain Headache Rep 2008;12:56-61.

16. Sharma M. Behavioural interventions for preventing and treating obesity in adults. Obes Rev 2007:8:441-449.

17. Moreira MM, Souza HP, Schwingel PA, Sá CK, Zoppi CC. Effects of aerobic and anaerobic exercise on cardiac risk variables in overweight adults. Arq Bras Cardiol 2008;91:200-206.

18. Schürks M, Rist PM, Bigal ME, Buring JE, Lipton RB, Kurth T. Migraine and cardiovascular disease: systematic review and meta-analysis. BMJ 2009; 339: 3914

19. Mahler DA, Horowitz MB. Clinical evaluation of exertional dyspnea. Clin Chest Med 1994;15:259-269.

20. Gil-Gouveia R, Martins I. Validation of the Portuguese version of ID-Migraine. Headache 2009 DOI 10.1111/j.1526-4610.2009.01449.x

21. Stewart WF, Lipton RB, Dowson AJ, Sawyer J. Development and testing of the Migraine Disability Assessment (MIDAS) questionnaire to assess headache-related disability. Neurology 2001;56(Suppl):S20-S28.

22. Fragoso YD. MIDAS (Migraine Disability Assessment): a valuable tool for work-site identification of migraine in workers in Brazil. Sao Paulo Med J 2002; 120:118-121.

23. De Vriendt T, Huybrechts I, Ottevaere C, Van Trimpont I, De Henauw S. Validity of self-reported weight and height of adolescents, its impact on classification into BMl-categories and the association with weighing behaviour. Int J Environ Res Public Health 2009;6:2696-2711.

24. Queiroz LP, Peres MFP, Kowacs F, et al. Chronic daily headache in Brazil: a nationwide population based study. Cephalalgia 2008;28:1264-1269.

25. Headache Classification Subcomitte of the International Headache Society. The Internacional Classification of Headache Disorders. $2^{\text {nd }}$ Edition. Cephalalgia 2004;24:1-160.

26. Kokkinos P. Physical activity and cardiovascular disease prevention: current recommendations. Angiology 2008;59 (Suppl): S26-S29. 